\title{
A genomic copy number variant analysis implicates the MBD5 and HNRNPU genes in Chinese children with infantile spasms and expands the clinical spectrum of $2 q 23.1$ deletion
}

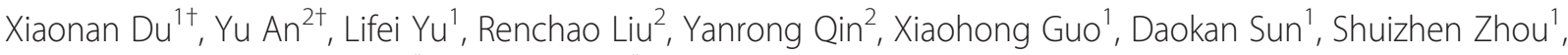 \\ Bailin $\mathrm{Wu}^{2,3}$, Yong-hui Jiang ${ }^{4^{*}}$ and Yi Wang ${ }^{1^{*}}$
}

\begin{abstract}
Background: Infantile spasms (IS) is a specific type of epileptic encephalopathy associated with severe developmental disabilities. Genetic factors are strongly implicated in IS, however, the exact genetic defects remain unknown in the majority of cases. Rare mutations in a single gene or in copy number variants (CNVs) have been implicated in IS of children in Western countries. The objective of this study was to dissect the role of copy number variations in Chinese children with infantile spasms.
\end{abstract}

Methods: We used the Agilent Human Genome CGH microarray $180 \mathrm{~K}$ for genome-wide detection of CNVs. Real-time qPCR was used to validate the CNVs. We performed genomic and medical annotations for individual CNVs to determine the pathogenicity of CNVs related to IS.

Results: We report herein the first genome-wide CNV analysis in children with IS, detecting a total of 14 CNVs in a cohort of 47 Chinese children with IS. Four CNVs (4/47=8.5\%) (1q21.1 gain; 1q44, 2q31.1, and 17p13 loss) are considered to be pathogenic. The CNV loss at 17p13.3 contains PAFAH1B1 (LIS1), a causative gene for lissencephaly. Although the CNVs at 1q21.1, 1q44, and 2q23.1 have been previously implicated in a wide spectrum of clinical features including autism spectrum disorders (ASD) and generalized seizure, our study is the first report identifying them in individuals with a primary diagnosis of IS. The CNV loss in the $1 \mathrm{q} 44$ region contains HNRNPU, a strong candidate gene recently suggested in IS by the whole exome sequencing of children with IS. The CNV loss at 2q23.1 includes MBD5, a methyl-DNA binding protein that is a causative gene of ASD and a candidate gene for epileptic encephalopathy. We also report a distinct clinical presentation of IS, microcephaly, intellectual disability, and absent hallux in a case with the 2q23.1 deletion.

Conclusion: Our findings strongly support the role of CNVs in infantile spasms and expand the clinical spectrum associate with 2q23.1 deletion. In particular, our study implicates the HNRNPU and MBD5 genes in Chinese children with IS. Our study also supports that the molecular mechanisms of infantile spasms appear conserved among different ethnic backgrounds.

Keywords: Infantile spasms, Copy number variants, Array CGH, Autism spectrum disorders, MBD5, HNRNPU

\footnotetext{
*Correspondence: yong-hui.jiang@duke.edu; yiwang@shmu.edu.cn

${ }^{\dagger}$ Equal contributors

${ }^{4}$ Division of Medical Genetics, Department of Pediatrics and Neurobiology, Duke University School of Medicine, 905 S. LaSalle ST, Durham, NC 27710, USA

'Division of Neurology, Children's Hospital of Fudan University, 399 Wan Yuan Road, Shanghai 201102, China

Full list of author information is available at the end of the article
}

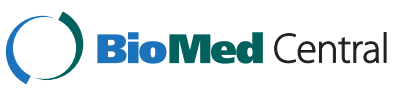

(c) 2014 Du et al.; licensee BioMed Central Ltd. This is an Open Access article distributed under the terms of the Creative Commons Attribution License (http://creativecommons.org/licenses/by/2.0), which permits unrestricted use, distribution, and reproduction in any medium, provided the original work is properly credited. The Creative Commons Public Domain Dedication waiver (http://creativecommons.org/publicdomain/zero/1.0/) applies to the data made available in this article, unless otherwise stated. 


\section{Background}

Infantile spasms(IS; also known as West syndrome) is a severe and specific type of epilepsy syndromes or epileptic encephalopathies that presents in early infancy. IS is characterized by the early onset (4-8 months of age) of the epileptic form of spasm, a distinct hypsarrhythmia on EEG, and poor developmental outcome [1]. The incidence of IS ranges from 0.25 to 0.4 per 1000 living births in Western countries. The prevalence of IS in Chinese children is not known but is estimated to be similar to that observed in the Caucasian population. Due to its refractory nature to most antiepileptic treatments and its frequent association with poor cognitive development, IS is one of the most devastating epileptic encephalopathies and neurological disorders of infancy and early childhood. Interestingly, IS has been shown to be strongly associated with autism spectrum disorders (ASD) [2]. Infantile spasms is a prominent clinical feature in several high profile monogenic syndromes such as tuberous sclerosis complex (TSC). Mutations in a growing number of genes have also been reported in individuals with nonsyndromic infantile spasms by medical re-sequencing or whole exome sequencing projects [3-5]. These genes include $A R X, C D K L 5$, FOXG1, GRIN1, GRIN2A, MAGI2, MEF2C, SLC25A22, SPTAN1, CACNA1A, CHD2, FLNA, NEEDL4, and STXBP1. Despite these findings, the causes for the majority of infantile spasms cases remain unknown. Recently, rare and recurrent genomic copy number variants (CNVs) have been implicated in intellectual disabilities, ASD, and other neuropsychiatric disorders. Many of these same CNVs have also been implicated in individuals with generalized epilepsy in Caucasian population [6-11]. However, the role of CNVs in IS has not been fully investigated. The clinical presentations of IS in Chinese children remain poorly characterized. There are few published reports on genomic or genetics studies of IS in Chinese children. We hypothesized that CNVs also contribute significantly to the susceptibility of IS in Chinese children. We conducted the first genome-wide copy number variation analysis in 47 Chinese children with IS using an array comparative genomic hybridization (array $\mathrm{CGH}$ ) technique. We detected a total of $364 \mathrm{CNVs}$ by array-CGH and validated 14 rare, inherited or de novo CNVs by further molecular experiments in this cohort. Genomic and medical annotations provided evidence that support the pathogenicity of several new CNVs, specifically, those in the HNRNPU and MBD5 genes, in IS.

\section{Methods}

\section{Study subjects}

The study was approved by the institutional review board (IRB) of the Children's Hospital of Fudan University. All the photographs of the children with or without eyes blocked have consent from their parents. All samples and information were collected after informed consent was obtained from the parents. The diagnosis of infantile spasms was made based on an assessment of clinical seizure presentation and electroencephalography (EEG) recorded by a pediatric neurologist with experience in the clinical diagnosis of infantile spasms (Additional file 1: Table S1). All patients included in this study had cranial magnetic resonance imaging (MRI), G-band karyotype and basic metabolic screening tests. The detailed medical findings and family history were also obtained. All patients with a documented history of infection in the central nervous system, a significant history of hypoglycemia, hypoxic ischemic encephalopathy, extreme premature birth, or other documented non-genetic insults were excluded. In addition, any cases with a clinical diagnosis of neurocutaneous syndromes such as tuberous sclerosis complex or other known genetic syndromes were not enrolled in this study.

\section{Comparative genomic hybridization or microarray analysis}

The array CGH was performed using an Agilent Human Genome CGH microarray $180 \mathrm{~K}$ kit (Agilent Technologies Inc. Shanghai, China) with a resolution of $6.4 \mathrm{~kb}$. For each sample, $1.5 \mu \mathrm{g}$ of genomic DNA was used for each array $\mathrm{CGH}$ experiment. The array $\mathrm{CGH}$ experiments were performed according to the manufacturer's instruction as described previously [12]. Briefly, genomic DNA from patients and controls was digested with the restriction enzymes $\mathrm{A} l u \mathrm{I}$ and RsaI (Promega) and fluorescently labeled with Cy5 (patients) or Cy3 (controls) using the Agilent DNA Labeling Kit. Labeled DNAs were combined, denatured, pre-annealed with Cot- DNA (Invitrogen) and blocking reagent (Agilent), and then hybridized to the arrays for 40 hours in a rotating oven (Agilent Technologies) at $65^{\circ} \mathrm{C}$ and a speed of $20 \mathrm{rpm}$. After performing the hybridization step and the recommended washes, the arrays were scanned at $5 \mu \mathrm{m}$ resolution with an Agilent G2505A scanner. The images were analyzed using the Feature Extraction software (Agilent Technologies, Shanghai, China). All array data that passed the quality metrics were further processed by the DNA Analytics software.

\section{Array CGH data analysis and CNV calling}

Array CGH data were analyzed using the Cytogenomics v2.5 software (Agilent Technologies, CA,USA). The QC metrics table was used to check the signal intensities and background noise. A DLR (Derivative Log Ratio) score above 0.20 was set as the cutoff criteria and those with below DLR 0.20 score indicate poor quality of array data and possibility of false CNV calling. CNV calls were performed using the ADM2 algorithm with a sensitivity threshold of 6.0 and a minimum of 5 probes. The non- 
benign CNVs were identified using common CNV filter including Database of Genomic Variants (DGV) and published CNV dataset from Chinese Han individuals.

\section{Validation of CNVs by quantitative real-time PCR (qPCR)}

For each $\mathrm{CNV}$ identified in this study, we confirmed the $\mathrm{CNV}$ gain or loss using quantitative PCR (qPCR) in probands and their parents. The primers used for qPCR were derived from the candidate genes within the CNVs that were also related to genetic disease in the OMIM database. Three to five primer pairs for each gene were selected for quantitative PCR (qPCR). The sequence of these primer pairs are listed in Additional file 1: Table S2. PCR reactions were performed in a volume of $10 \mu \mathrm{l}$ containing $5 \mu \mathrm{l} \mathrm{SYBR}$ Green I Master mix (Toyota, China), $0.4 \mathrm{mM}$ primers, and approximately $25 \mathrm{ng}$ template cDNA. The housekeeping gene HMBS was used as an endogenous control for normalization. The reactions for each sample were performed in triplicate using a StepOnePlus ${ }^{\text {TM }}$ Real-Time PCR System (Applied Biosystems ${ }^{\circ}$ ). The thermal profile for the qPCR was as follows: a pre-incubation step of $45 \mathrm{sec}$ at $95^{\circ}$ $\mathrm{C}$, followed by 40 cycles of $5 \mathrm{sec}$ at $95^{\circ} \mathrm{C}, 30 \mathrm{sec}$ at $60^{\circ} \mathrm{C}$, and $30 \mathrm{sec}$ at $72^{\circ} \mathrm{C}$. The raw data were analyzed using StepOne $^{\mathrm{ma}}$ Software v2.1. Amplification levels were calculated using the $\Delta \Delta \mathrm{Ct}$ method according to the manufacturer's instructions.

\section{Sequence analysis of $M B D 5$ and $O R C 4$}

Primers flanking the MBD5 (NM_018328) and ORC4 (NC_000002) exon-intron junctions were designed to amplify the exons of these two genes using the Primer 3 online program. The sequences of these primers are listed in the Additional file 1: Table S3. Touchdown PCR was performed for all of the other amplicons. Briefly, cycling conditions comprised 10 cycles of: $30 \mathrm{sec}$ denaturation at $95^{\circ} \mathrm{C}, 30 \mathrm{sec}$ annealing and $72^{\circ} \mathrm{C}, 40 \mathrm{sec}$ for primer extension. The annealing temperature was decreased $0.5^{\circ} \mathrm{C}$ every second cycle from $63^{\circ} \mathrm{C}$ to $58^{\circ} \mathrm{C}$, followed by 25 additional cycles with an annealing temperature of $58^{\circ} \mathrm{C}$. The direct sequencing of $\mathrm{PCR}$ products was carried out using an ABI Prism Big Dye System (Applied Biosystems). The raw sequencing data were processed, and variant calling was performed using the Mutation Surveyor v3.97 software program (SoftGenetics, PA, USA).

\section{Statistical analysis}

Data were analyzed using SPSS (Statistical Package for the Social Sciences) version 18.0 statistical software (SPSS Inc., Chicago, IL). A one-way ANOVA test followed by LSD was used when comparing three groups. A p value of $\mathrm{p}<0.05$ (two-tailed) was considered significant.

\section{Results}

\section{Study subjects}

A total of 47 patients (24 males and 23 females) with a clinical diagnosis of IS were enrolled in this study (Additional file 1: Table S1). The diagnosis of IS was supported by both a characteristic clinical presentation of seizures and an abnormal EEG with hypsarrhythmia that is unique to IS in 45 patients. Two patients exhibited clinical presentations of infantile spasms without a typical EEG pattern of hypsarrhythmia in the recording at the time of enrollment (aged 8 months-old and 13 months-old). The mean age of subjects at enrollment was $20.2 \pm 19.7$ months. The average onset of infantile spasms was $6.3 \pm 2.9$ months.

All patients displayed developmental delay and intellectual disability. Brain structural MRI analyses were performed for all participants. Abnormalities including pachygyria, corpus callosum dysplasia, enlarged CSF space, diffuse and abnormal cortical migration, and atrophy were found in 5 patients (Additional file 1: Table S1). Other congenital anomalies, including heart defects and limb anomalies, were found in 7 out of 47 cases. The parents of all the probands were reported to be healthy and did not have history of seizure disorders. One family (S133) had two affected boys ( 2 and 8 years-old) with IS, motor development delay, speech and cognitive impairment.

\section{Genome-wide copy number variation analysis}

G-band karyotyping and routine clinical biochemical screening tests for inborn errors of metabolism were performed in all participants to rule out common known genetic and metabolic conditions. No specific abnormalities were identified in these tests. An array CGH analysis was performed for all probands using an Agilent Human Genome CGH microarray $180 \mathrm{~K}$ array. The CNV calling and filtering were described previously [12]. A Han Chinese specific CNV dataset obtained from multiple sources was used for the CNV analyses [13-15]. The CNVs called by the computational program were validated primarily by real-time quantitative PCR (qPCR) analyses. A total of 364 $\mathrm{CNVs}$ were identified from 47 individuals $(7.7 \mathrm{CNVs} /$ per case). After filtering and annotation, $14 \mathrm{CNVs}$ (5 deletions and 9 duplications) were further validated by molecular experiment by the real time $\mathrm{qPCR}$ using the primers within the genes mapped to the deleted or duplicated intervals (Additional file 1: Table S2). The sizes of the CNVs ranged from $115 \mathrm{~kb}$ to $4.1 \mathrm{Mb}$. One proband (S34) had two CNVs while the rest of the cases had a single CNV. Parental testing was performed on both parents for 12 CNVs. Six CNVs were de novo and 6 were either maternally or paternally inherited. In other two families (S2 and S75), parental test was not performed because either one or both parents were not available for testing.

We conducted genomic and medical annotations for each $\mathrm{CNV}$ that were identified and confirmed from this 
cohort. The genomic annotation was performed by reviewing the function of the candidate genes residing within the deleted or duplicated interval of the CNVs and absence in the DGV. The medical annotation was performed by reviewing the clinical reports related to each of the CNVs in PubMed, the candidate gene(s) in $\mathrm{CNVs}$ relevant to the OMIM entries, and the function of these genes in the evidence provided by other model organisms or experimental systems. Through these analyses, we determined the pathogenicity of the CNVs in IS based on a comprehensive assessment of the existing clinical data, the size of the CNV, the gene content of the CNV, and the inheritance of the CNV. These CNVs were placed into 3 classes based on the evidence supporting their pathogenicity in IS: 1) pathogenic; 3) unknown clinical significance; and 3) probably benign (Table 1). The molecular and clinical characteristics of each class of CNVs are discussed below.

\section{Pathogenic CNVs}

Four CNVs were classified as pathogenic (Table 1). In case S100, a de novo 115-kb deletion was detected in the 17p13.3 region (chr17:2,405,454-2,520,464, www. genome.ucsc.edu; hg19, thereafter) in a boy diagnosed with IS (Figure 1A and D). The proximal breakpoint of the deletion is within intron 2 of METTL16, a gene that encodes a methyltransferase-like protein. But the exact function of this protein has not been determined biochemically. The distal breakpoint was within an intron 1 of PAFAH1B1 (LIS1), a gene known to cause lissencephaly and the feature of IS [16]. This patient developed IS at 4 months of age and the diagnosis of IS was supported by an EEG pattern of hypsarrhythmia. The patient had mild dysmorphic facial features including hypertelorism and micrognathia (Figure 1B). Structural brain MRI analysis revealed diffuse and generalized pachygyria and grade III to IV lissencephaly (Figure $1 \mathrm{C}$ ) that is consistent with the clinical findings in other patients with similar defects of PAFAH1B1. Generalized seizures and infantile spasms are common clinical features associated with deficiency of PAFAH1B1 [16,17].

In case S37, a de novo 2.1-Mb deletion was found in the 1q44 region (chr1:244,961,797-247,074,490) in a boy with a primary diagnosis of IS (Figure 2A and D). The patient developed IS at 5 months of age and the EEG indicated hypsarrhythmia and epileptiform of activity. Physically, he had a prominent forehead and small chin (Figure 2B). Structural brain MRI analysis showed delayed myelination and some degree of cortical dysplasia (Figure 2C). There was a history of developmental regression after the onset of IS. At 2 years of age, his language development was severely delayed. His behavioral profile was consistent with a clinical diagnosis of ASD. The deleted region contains 8 known genes including COX20, HNRNPU, EFCAB2, SMYD3, TFB2M, CNST, SCCPDH, and AHCTF1 (Figure 2A). Interestingly, a sequence variant at the splice acceptor site of HNRNPU was found in a patient with infantile spasms by whole exome sequencing (WES) in Epi4K project

Table 1 Rare and novel CNVs identified from Chinese infantile spasms children

\begin{tabular}{|c|c|c|c|c|c|c|c|c|}
\hline Subject & Sex & $\begin{array}{l}\text { Onset of IS } \\
\text { (month) }\end{array}$ & $\begin{array}{l}\text { EEG } \\
\text { (HYPS+/-) }\end{array}$ & $\begin{array}{l}\text { Genomic location/coordinates } \\
\text { (hg19) }\end{array}$ & $\begin{array}{l}\text { Genomic } \\
\text { event }\end{array}$ & Size & Inheritance & $\begin{array}{l}\text { Candidate } \\
\text { gene(s) }\end{array}$ \\
\hline \multicolumn{9}{|c|}{ Pathogenic } \\
\hline S100 & M & 4 & + & chr17:2,405,454-2,520,464 & Del & $115 \mathrm{~Kb}$ & De novo & PAFAH1B1 \\
\hline S37 & M & 5 & + & chr1:244,961,797-247,074,490 & Del & $2.1 \mathrm{Mb}$ & De novo & HNRNPU \\
\hline $\mathrm{S} 162$ & $\mathrm{~F}$ & 6 & - & chr2:147,953,313-152,061,251 & Del & $4.1 \mathrm{Mb}$ & De novo & MBD5 \\
\hline S67 & F & 10 & + & chr1:145,764,453-147,824,207 & Dup & $2.0 \mathrm{Mb}$ & De novo & CHD1L \\
\hline \multicolumn{9}{|c|}{ Unknown clinical significance } \\
\hline $\mathrm{S} 15$ & F & 2 & + & chr10:84,222,075-85,293,140 & Dup & $1.0 \mathrm{Mb}$ & Paternal & $N R G 3$ \\
\hline S34 & M & 5 & + & chrX:102,262,951-102,659,333 & Dup & $396 \mathrm{~kb}$ & Maternal & NGFRAP1 \\
\hline$\$ 134$ & F & 4 & + & chr17:14,111,754-15,442,119 & Del & $1.3 \mathrm{Mb}$ & Paternal & PMP22 \\
\hline $\mathrm{S} 163$ & F & 4 & + & chrX:6,451,691-8,115,193 & Dup & $1.6 \mathrm{Mb}$ & Paternal & STS,VCX3A \\
\hline S165 & M & 5 & + & chr11:101,857,720-102,256,635 & Del & $398 \mathrm{~kb}$ & De novo & YAP1 \\
\hline \multicolumn{9}{|c|}{ Probably benign } \\
\hline S2 & M & 3 & + & chr2:216,898,976-217,160,487 & Dup & $261 \mathrm{~kb}$ & Not determined & \\
\hline $\mathrm{S} 34$ & M & 5 & + & chr2:137,826,656-138,048,583 & Dup & $221 \mathrm{~kb}$ & Paternal & \\
\hline S42 & M & 4 & + & chr4:48,983,002-49,063,489 & Dup & $80 \mathrm{~kb}$ & Paternal & \\
\hline S75 & M & 6 & + & chr6:118,989,529-120,238,639 & Dup & $1.2 \mathrm{Mb}$ & Not determined & \\
\hline S133 & $M$ & 13 & - & chr8:135,644,952-135,791,363 & Dup & $146 \mathrm{~Kb}$ & De novo & \\
\hline
\end{tabular}




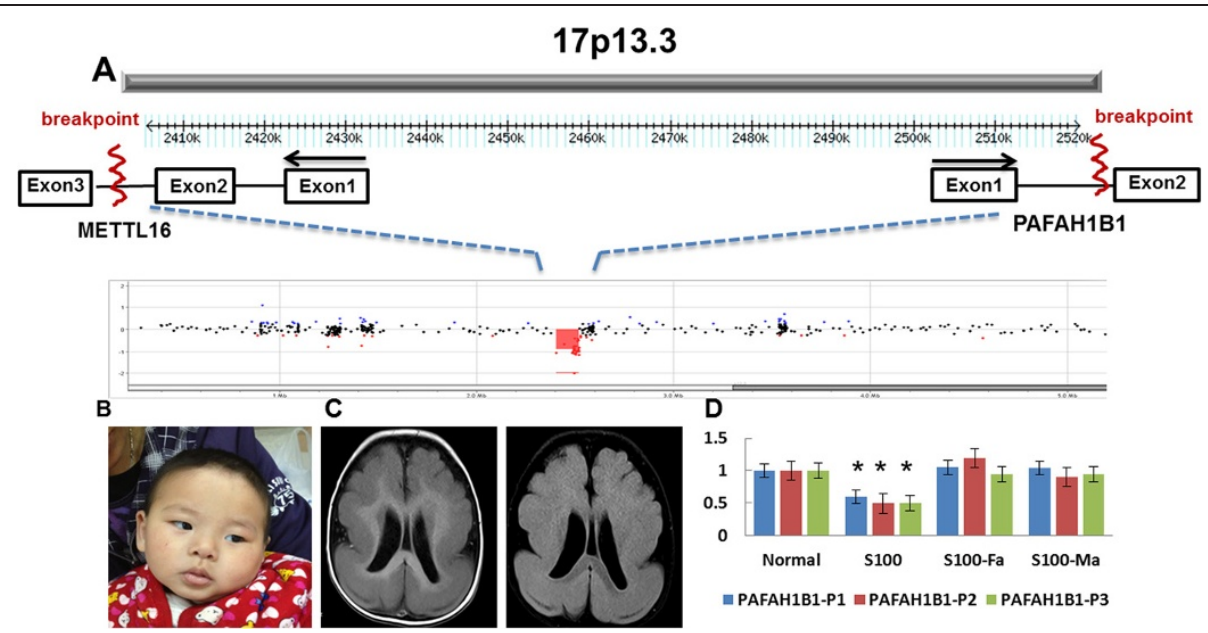

Figure 1 A patient (S100) with a 115-kb microdeletion at 17p13.3 that disrupts the PAFAH1B1 (LIS1) gene. A) A local view of the 17p13.3 deletion. The proximal breakpoint is within intron 2 of METTL16, a gene that encodes methyltransferase-like 16 protein whose exact function has not been characterized. The distal breakpoint is within intron 1 of PAFAHIBI (LIS1), a known causative gene for lissencephaly. The black arrows are the direction of transcription. B) The clinical features of a patient with a prominent forehead and micrognathia. C) Structural MRI analysis showed grade III lissencephaly. D) Analyses by qPCR confirmed that the copy number loss in this patient was de novo using three different primers (P1-P3) within the PAFAH1B1 and analyses of both parents. ${ }^{*} p<0.01$, proband vs parents and control.

$[14,18]$. Our findings thus provide further support that HNRNPU in the $1 \mathrm{q} 44$ region is pathogenic or causative gene for infantile spasms in this case.

We also detected a deletion in the $2 \mathrm{q} 23.1$ region including $M B D 5$ gene in case S162 (Table 1 and Figure 3A) and a duplication in the 1q21.1 region in case S67 (data not shown), respectively. The CNVs in these two regions have previously been implicated in a wide spectrum of clinical presentations that include ASD, intellectual disability and seizure, but not specifically IS [19-21]. In case $\mathrm{S} 162$, a $4.1-\mathrm{Mb}$ deletion in the $2 \mathrm{q} 23.1$ region was found in a 7 month-old female (Figure $3 \mathrm{~A}$ and $\mathrm{B}$ ). The size of the deletion was moderate compared to other cases in the literature that ranged from $100 \mathrm{~kb}$ to $6 \mathrm{MB}$ in the region [20]. The seizures in proband started at 4 days of age and then transformed into spasms at 6 months of age. An EEG study indicated the presence of a bilateral sharp wave and spike slow wave complex at

A
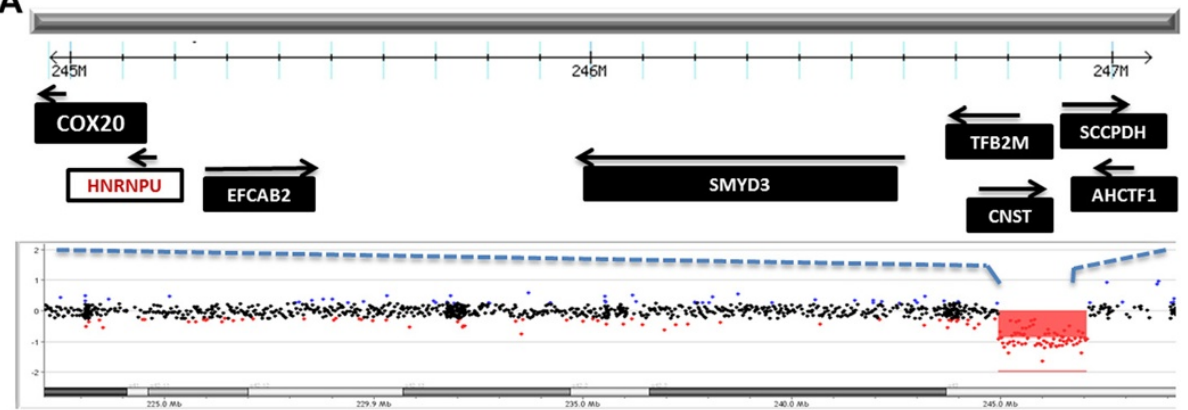

B
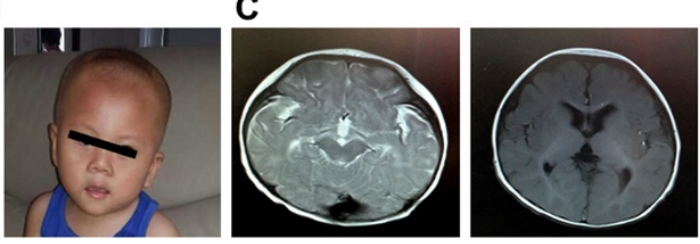

D

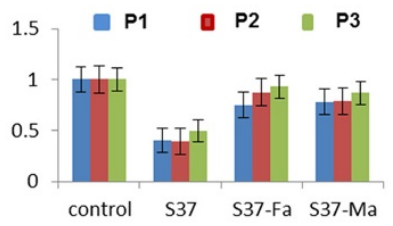

Figure 2 The proband of S37 with a 2.1-Mb microdeletion at 1q44 that disrupts the infantile spasms candidate gene HNRNPU reported by the WES study. A) A local view of the 1q44 deletion and genes in the deleted interval. The black arrows are the direction of transcription of genes. B) The clinical features of a proband with a dysmorphic face. C) Structural MRI analysis showed delayed myelination in the brain. D) qPCR confirmed the copy number loss in probands using three different primers (P1-P3) within HNRNPU. ${ }^{*} \mathrm{p}<0.01$, proband vs parents and control. 


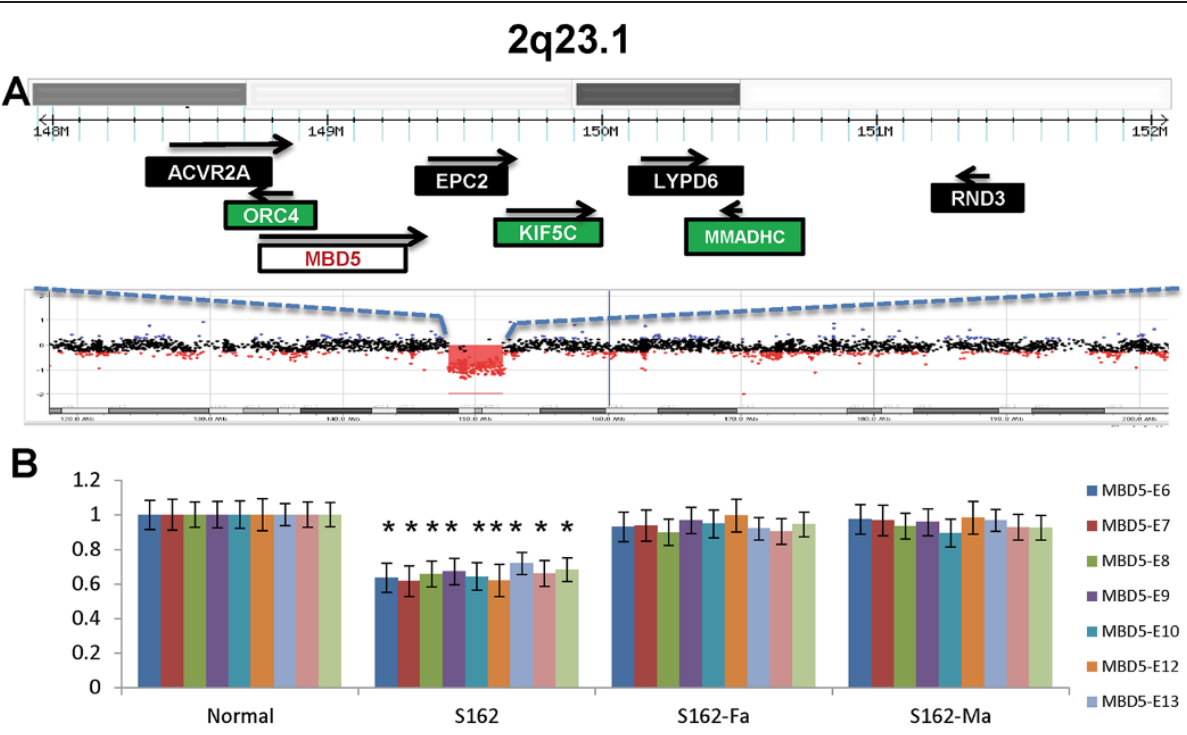

C

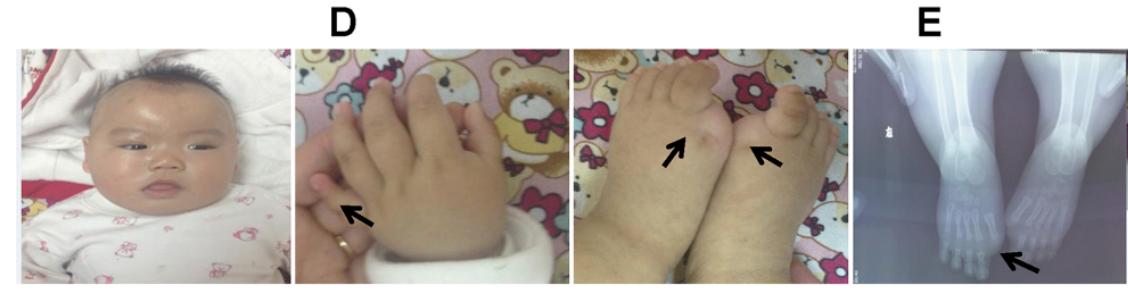

Figure 3 A patient from S162 with a 4.1-Mb microdeletion at 2q23.1 that disrupts the known ASD causative gene MBD5. A) A local view of the $4.1 \mathrm{Mb} 2 \mathrm{q} 31.1$ deletion and genes in the deleted interval. B) Analysis by qPCR confirmed the copy number loss and de novo event in the patient using 7 primers (MBD5E6-E13) from exons 5-13 of MBD5. C) The clinical features of a proband with a dysmorphic face, including a coarse face. D) Clinodactyly of the fifth finger, excessive fat pads of the second and middle fingers, and the absence of great toes. E) X-ray analyses showed the absence of the distal and proximal phalanges of the great toes. ${ }^{*} p<0.01$, proband vs parents and control.

8 months of age that was suggestive of hypsarrhythmia. Structural brain MRI analysis showed some degree of cortical dysplasia and microcephaly. She also had dysmorphic face including a broad forehead, arched eyebrows, and deep nasal bridge (Figure 3C). Her great toes were bilaterally absent (absent hallux) and the fifth fingers were short and exhibited clinodactyly (Figure 3D). An X-ray study revealed missing proximal and distal phalanges in the great toes but normal knee joints. She also had significant hypotonia, severe language delay, and suspected ASD diagnosis.

The 2q23.1 deletion has been reported in individuals with ASD, seizure, and developmental delay. However, the overall neurological presentations in our case appeared much more severe than in other individuals with similar sized deletions in 2q23.1 in three other major reports considering the degrees of hypotonia and the onset of seizures [20,22-24] (Table 2). Although the mild anomalies of hand and foot has been seen in most patients with MBD5 defect, the features of IS and the absent hallux limb anomaly have not been reported previously. We then tested the hypothesis that the sequence variants for the genes in the deleted interval of the non-deleted chromosome may modify or contribute to more severe and unique clinical presentations in this case. There are a total of 8 genes within the deleted intervals (chr2:147,953,313$152,061,251$ ) in our case (Figure 3A), including three classified as known disease-causing genes listed in the OMIM: MBD5, ORC4, and MMADHC. MBD5 is an important gene within the 2q23.1 region that was believed to be responsible for ASD, intellectual disabilities, developmental delays and seizures in 2q23.1 deletion because point mutations in $M B D 5$ shared the key neurological features with 2q23.1 deletion (Tab1e 2) [20,22-24]. ORC4 is a causative gene of a subtype of Meier-Gorlin syndrome (MGS), a rare autosomal recessive disorder characterized by severe intrauterine and postnatal growth retardation, developmental delay, microcephaly, bilateral microtia, and aplasia or hypoplasia of the patellae. In our case, the X-ray study did not reveal abnormal patellae. The clinical presentations are not consistent with the diagnosis of MGS. The MMADHC gene is responsible for the cobalmin (cbl)-D type of methylmalonic aciduria. The metabolic profile in our case did not suggest a defect in cobalmin metabolism. Because the functions of both MBD5 and $O R C 4$ are important for brain function, we tested whether 
Table 2 Comparison of clinical features of 2q23.1 deletion in this study and other cohorts or MBD5 specific mutation

\begin{tabular}{|c|c|c|c|c|c|}
\hline \multirow[t]{2}{*}{ Clinical Features } & \multicolumn{2}{|c|}{ MBD5-specific mutation ${ }^{20,22-24}$} & \multicolumn{2}{|c|}{ 2q23.1 Deletion ${ }^{20,22-24}$} & \multirow{2}{*}{$\frac{\text { Case in this study }}{+, \text { present; - absent }}$} \\
\hline & Number & Percentage & Number & Percentage & \\
\hline \multicolumn{6}{|l|}{ Neurological } \\
\hline Development delay & $20 / 21$ & $95 \%$ & $53 / 55$ & $96 \%$ & + \\
\hline Language impairment & $12 / 21$ & $57 \%$ & $38 / 55$ & $69 \%$ & + \\
\hline Seizure & $11 / 21$ & $52 \%$ & $32 / 55$ & $58 \%$ & + \\
\hline Infantile spasms & $0 / 21$ & 0 & $0 / 55$ & 0 & + \\
\hline Infantile hypotonia & $4 / 21$ & $19 \%$ & $23 / 55$ & $41 \%$ & + \\
\hline \multicolumn{6}{|l|}{ Growth/Endocrine } \\
\hline Short stature & $5 / 21$ & $24 \%$ & $25 / 55$ & $45 \%$ & - \\
\hline Local hirsutism & $0 / 21$ & 0 & $4 / 55$ & $7 \%$ & - \\
\hline \multicolumn{6}{|l|}{ Craniofacial abnormalities } \\
\hline Coarse face & $0 / 21$ & 0 & $3 / 55$ & $5 \%$ & + \\
\hline Broad forehead & $3 / 21$ & $14 \%$ & $4 / 55$ & $7 \%$ & + \\
\hline Microcephaly & $1 / 21$ & $5 \%$ & $26 / 55$ & $47 \%$ & $+(<2 \mathrm{SD})$ \\
\hline Synophrys & $2 / 21$ & $9 \%$ & $10 / 55$ & $18 \%$ & + mild \\
\hline Nasal abnormalities & $7 / 21$ & $33 \%$ & $35 / 55$ & $64 \%$ & + \\
\hline Open mouth & $3 / 21$ & $14 \%$ & $23 / 55$ & $42 \%$ & + \\
\hline Downturned corners of the mouth & $3 / 21$ & $14 \%$ & $17 / 55$ & $31 \%$ & + \\
\hline Macroglossia or protruding tongue & $2 / 21$ & $9 \%$ & $6 / 55$ & $11 \%$ & - \\
\hline Dental abnormalities & $4 / 21$ & $19 \%$ & $13 / 55$ & $24 \%$ & \\
\hline Skeletal abnormalities & & & & & + \\
\hline Small hands and feet & $1 / 21$ & $5 \%$ & $23 / 55$ & $42 \%$ & + \\
\hline Clinodactyly, 5th finger & $2 / 21$ & $9 \%$ & $22 / 55$ & $40 \%$ & + \\
\hline Brachydactyly & $0 / 21$ & 0 & $13 / 55$ & $24 \%$ & + \\
\hline Short fifth digit of hands/feet & $1 / 21$ & $5 \%$ & $14 / 55$ & $25 \%$ & + \\
\hline Absent hallux & $0 / 21$ & 0 & $0 / 55$ & 0 & + \\
\hline Behaviors & & & & & - \\
\hline Autistic feature & $13 / 21$ & $62 \%$ & $44 / 55$ & $80 \%$ & + \\
\hline Sleep disturbance & $5 / 21$ & $24 \%$ & $17 / 55$ & $31 \%$ & ND \\
\hline Self-injurious behavior & $2 / 21$ & $9 \%$ & $17 / 55$ & $31 \%$ & + \\
\hline Other & & & & & - \\
\hline Cardiovascular abnormalities & $1 / 21$ & $5 \%$ & $4 / 55$ & $7 \%$ & - \\
\hline Urogenital abnormalities & $1 / 21$ & $45 \%$ & $1 / 55$ & $2 \%$ & - \\
\hline
\end{tabular}

ND, not documented.

sequence variants of $M B D 5$ and $O R C 4$ in the non-deleted allele were present in this patient. We sequenced the coding exons of MBD5 and ORC4. The primers used for sequencing and PCR are included in Additional file 1: Table S3. No significant sequence variants were identified in all coding exons of $M B D 5$ and ORC4 genes.

In case S67, a de novo $2 \mathrm{Mb}$ duplication at 1q21.1 (chr1:145,764,453-147,824,207) was found in a 4-yearold girl with a diagnosis of IS. The duplication spanned the 1q21.1 distal region but did not include the TAR (thrombocytopenia with absent radius) syndrome region.
The size of this duplication is larger than many of the cases described by Brunetti et al. [25] and Mefford et al. [26] but is similar to other recently reported cases [27]. The probe coverage may contribute to the discrepancy for the estimated size of duplication in different reports. Duplication at 1q21.1 has been implicated in a wide spectrum clinical presentations including ASD, congenital heart defects, seizures, schizophrenia, and developmental delay [25-27]. In our case, the proband developed IS at 8 months of age with EEG of hypsarrhythmia epileptiform activity. The spasms were poorly controlled and progressed 
to Lennox-Gastaut syndrome at a later age. Structural brain MRI analysis uncovered mild delayed myelination and enlarged ventricles. Her cognitive development regressed significantly after the onset of spasms. There are more than 20 genes within the $2 \mathrm{Mb}$ duplicated interval and the knowledge for which gene or genes are responsible for neurological phenotypes is limited. CHD1L, a gene encoding chromodomain helicase DNA binding protein 1-like, was mapped to this interval.

\section{CNVs of unknown clinical significance}

Five novel de novo or inherited CNVs were considered to have potential roles in IS because of their size and the known function of the gene in the brain. However, the exact clinical relevance could not be determined with confidence. These CNVs include the following: 1) a paternally inherited 1.07 Mb duplication in chromosome 10q22.3 that contains NRG3, a gene implicated in schizophrenia and other neuropsychiatric diseases [28,29], 2) a maternally inherited $396 \mathrm{~kb}$ duplication at Xq22.1 (chrX:102,262,951$102,659,333)$ in a boy (S34). The duplication contains NGFRAP1 (NADE), a gene that encodes a nerve growth factor receptor-associated protein. The NGFRAP1 protein notably interacts with TSC1 [30], a protein responsible for TSC, a genetic disorder in which infantile spasms is a common feature; 3) a paterally inherited $1.6 \mathrm{Mb}$ duplication at Xp22.31 in S163 that contains two OMIM genes of STS and $V C X 3 A$ (chrX:6,451,691-8,115,193). The deletion including STS and $V C X 3 A$ was found in two cases with ichthyosis and/or mental retardation. The duplication of Xp22.31 region has been reported but the clinical relevance has not been determined [31,32]. The function of STS and VCX3A in brain is not known; 4) a paternally inherited deletion in the $17 \mathrm{p} 12$ region that contains PMP22, a gene that causes a hereditary neuropathy with liability to pressure palsies (HNPP, OMIM 162500) [33]; and 5) a de novo 398-kb deletion in the 11q22.1 region in S165 (chr11:101,857,720-102,256,635) that contains a gene encoding YAP1, a protein that associates with 143-3 in an AKT-dependent manner that is important for brain function [34].

Although these CNVs are rare and novel, their roles in the clinical presentation of IS are not immediately clear. In the case with the CNV gain at 10q23.1, the Neuregulin 3 (NRG3) gene, a family of neurally expressed proteins that perform a wide range of functions in the developing nervous system, mapped within this region. The breakpoint of duplication was within the middle of NRG3 coding exons. Therefore, it is not clear what was the impact of this duplication to the expression of NRG3. There are numerous reports suggesting that NRG3 contributes to the susceptibility of schizophrenia and other neuropsychiatric disorders $[28,35,36]$. In our case, because the duplication is inherited from the healthy parent, the role of this duplication in proband related to IS could not be determined with confidence. In the case S34, a $396 \mathrm{~kb}$ duplication in $\mathrm{X}$ chromosome containing NGFRAP1(NADE) gene in boy was inherited from the healthy mother. The similar duplication has not been reported before associated with disease in humans. The function of NGFRAP1 related to TSC1 suggested that the NGFRAP1 may be a risk factor for the IS. The similar scenario is applied to the case of S165 with a de novo 398-kb deletion in the 11q22.1 region. YAP1, a protein important for brain function is mapped to the region but the similar deletion has not been associated with disease phenotype in human. In case S134, the father carrying the same deletion containing PMP22 gene appears healthy and does not have clinical symptoms, suggesting a diagnosis of PMP22-related HNPP at the age of 30s. It is possible that father may have a late onset of HNPP. There is no report indicating that seizure or IS is a feature of individuals with HNPP [33]. Therefore, it is less likely that $P M P 22$ related $\mathrm{CNV}$ found in proband is a risk factor for IS and additional investigation is warranted to search for another possible cause in this case.

\section{Probably benign CNVs}

Five CNVs in cases of S2, S34, S42, S75, and S133 are probably benign or non-pathogenic to IS despite their rare occurrence in the controls. The sizes of these CNVs were small. There are no functionally significant genes within these CNVs. The inheritance is either de novo, inherited, or unknown. We thus reasoned that these CNVs are more likely to be benign or very unlikely to contribute to IS.

\section{Discussion}

Here, we report the first genome copy number variation analysis in a cohort of 47 Chinese children with IS. Our study identified four pathogenic CNVs (17p13.3, 1q44, 2q23.1, and 1q21.1) involving genes of PAFAH1B1(known), HNRNPU (known), MBD5 (new), and CHD1L (new) in 47 Chinese children with a primary diagnosis of IS. The 17q13.3 deletion containing PAFAH1B1(LIS1) gene is known to be responsible for IS [16]. The finding of CNVs at $1 \mathrm{q} 44,2 q 23.1$, and $1 \mathrm{q} 21.1$ in IS is novel and reported for the first time. The overall positive detection rate for pathogenic CNV in this cohort was $8.5 \%$ (4/47), which is similar or slightly higher than the rates reported in other studies of IS [8,37]. The detection rate of epilepsy syndromes other than infantile spasms or epileptic encephalopathy varied $[9,11]$. This difference is most likely related to patient selection in different studies. As noted, the patients in our cohort have a higher percentage of congenital anomalies that may contribute to the higher positive detection rate of CNVs in our study.

The identification of a small 115-kb microdeletion disrupting PAFAH1B1(LIS1) gene is consistent with the clinical presentations of lissencephaly and IS [16]. The CNV at 
1q44 containing HNRNPU has been reported in cases with seizures, brain malformation, and developmental delay $[38,39]$. However, an association of this CNV with IS has not been reported previously. More importantly, a sequence in the splice acceptor site of HNRNPU in individual with IS was recently reported by WES in epi4K project [4]. Together, these results indicate a pathogenic role of the 1q44 deletion, and primarily, HNRNPU deficiency in IS. The CNVs at $1 \mathrm{q} 21.1$ and $2 \mathrm{q} 23.1$ have been previously implicated in a wide spectrum of clinical presentations including intellectual disabilities, congenital anomalies, ASD, and generalized seizures but not in IS $[19,20]$. These may simply be due to the clinical information in these reports were typically extracted from limited medical records for the subjects in the studies. In other cases, the features of IS may be age dependent and missed at time of recruitment. Our findings then support a careful review of clinical records or re-evaluation clinically to determine whether IS is more prevalent in 2q23.1 deletion cases. The MBD5 gene within the 2q23.1 deletion has been shown to be the primary gene responsible for neurological features of ASD, seizures, and intellectual disability [20,22,23]. Recently, a deleterious mutation in $M B D 5$ was found in a patient with epileptic encephalopathy [40]. The CHD1L gene in 1q21.1 is interesting candidate. The known functions of $C H D 1 L$ in the literature are primarily related to cancers [26]. However, it was noted that $\mathrm{CHD} 2$, a protein that belongs to the same family as CHD1L, has been strongly implicated in epileptic encephalopathy in several recent studies [40,41]. Together with our study, these results support a conclusion that MBDS and HNRNPU play an important role in the susceptibility to IS and epileptic encephalopathy. Our study is the first to report these pathogenic CNV in Chinese children. These findings then suggest that, despite the different genome architecture of CNVs between Caucasian and Chinese populations [13-15], the pathogenic CNVs appear conserved between two populations.

The clinical presentations of our case with a deletion at 2q23.1 shares similar feature but has distinct and more severe neurological presentations than other cases with similar sized deletions [20,22-24] (Table 2). These may suggest additional genomic variants in genome may modify clinical phenotypes. The hypotonia appeared to be more prominent and the onset of seizure was much earlier than in other cases reported in literature. Interestingly, while mild finger anomalies are common in patients with 2q23.1 deletions, the absence of the great toes has not been reported previously. The physical sign of absence of the great toes is not suggestive of other causes, such as amniotic band sequence, because the second toes are apparently larger than expected (Figure 3D). The absence of the great toes is a rare clinical manifestation in literature. The interesting question is whether this is an expanded clinical feature of the 2q23.1 deletion syndrome or whether it has a different cause other than the 2 q23.1 deletion.

The combination of keyword searching using 'seizure' and 'absent great toes' in the London dysmorphology database, a comprehensive dysmorphology database for genetic syndromes, revealed no entries [42]. A search of PubMed using the key words 'absent great toes' revealed only one case report of hypoplasia of hallux that was associated with microphthalmia, facial anomalies, microcephaly, thumb hypoplasia, and agammaglobulinemia [43]. These presentations are clearly different from our case. It remains to be seen whether the feature of absent great toes is unique to the Chinese children with $M B D 5$ related 2 q23.1 deletions. If this is caused by a different genetic cause, we speculate that the unique presentation of microcephaly, infantile spasms, and absent hallux may define a new genetic syndrome requiring further delineation in additional cases.

To our knowledge, there are three genome-wide CNV studies specifically to IS in the literature [7,8,37]. Two similar studies in Caucasian children reported previously [8,37]. Another report analyzed CNVs using data from cases with IS that were referred to a clinical diagnostic laboratory [7] (Table 3). A large WES study on IS was reported as part of the epi4K project on epileptic encephalopathy $[4,18]$. Using data from a CMA performed in a clinical genetics laboratory, Paciokowski et al. reported 11 CNVs in 11 patients referred for a clinical genetics evaluation of IS [7]. Mefford et al. included 44 infantile spasms cases in a large-scale CNV analysis for 315 children with epileptic encephalopathy. Three pathogenic CNVs were identified in 44 cases of IS $(3 / 44=6.9 \%)$ [37]. These include a de novo deletion in CDKL5, an inherited duplication of 16p11.2, and an inherited deletion of $12 \mathrm{q} 12$. In the last study, Tiwari et al. identified 4 known CNVs in 11 IS cases. These include a de novo duplication of maternal origin in the 15q11-q13 region, a deletion of Xp22.13 containing CDKL5, a deletion of $16 \mathrm{p} 11.2$ and an inherited deletion of $2 \mathrm{q} 32.2$ [8]. Although the sample size was still small, our study provides further evidence from a different population supporting the role of CNVs in the etiology of IS. More importantly, the identification of CNVs in 1q44 and deletion of 2q23.1 indicate that HNRNPU and MBD5 genes play significant roles contributing to the susceptibility of IS.

MBD5 belongs to the methyl-CpG DNA binding protein family that includes $M e C P 2$, a gene that causes Rett syndrome [44]. MBD5 is highly expressed in the brain but its function in brain remains uncharacterized [45]. Mice with null mutations in $M b d 5$ displayed growth retardation, small brain size, and early postnatal lethality [45]. These results indicate that $M b d 5$ is important for brain development but the exact role of $M b d 5$ remains 
Table 3 Comparison between this study and published CNV and WES studies of infantile spasms

\begin{tabular}{|c|c|c|c|c|c|}
\hline \multicolumn{5}{|l|}{ CNV studies } & \multirow{2}{*}{$\begin{array}{l}\text { WES (epi4K) } 4,18 \\
\text { Epi4K Consortium \& Epilepsy } \\
\text { Phenome/Genome Project }\end{array}$} \\
\hline No of case & This study & Mefford, et al [37] & Tiwari, et al [8] & Paciokowski, et al [7] & \\
\hline & 47 & 44 & 13 & $\begin{array}{l}\text { N/A (clinical case series } \\
\text { from diagnostic lab) }\end{array}$ & $\begin{array}{l}\text { infantile spasms ( } n=149) \\
\text { Lennox-Gastaut syndrome } \\
(n=115) \text {. }\end{array}$ \\
\hline \multirow{15}{*}{$\begin{array}{l}\text { Pathogenic/Possible } \\
\text { pathogenic CNV }\end{array}$} & 4 & 3 & 4 & 11 & 329 de novo mutation \\
\hline & De novo: & De novo: & De novo: & De novo: & $\begin{array}{l}\text { Mutations in more than one } \\
\text { proband }\end{array}$ \\
\hline & 17p13 115 kb del & Xp22 290 kb del & $15 q 114.8 \mathrm{Mb}$ dup & 2p16.1 4.0 Mb del & SCN1A; STXBP1; GABRB3; \\
\hline & $1 \mathrm{q} 442.1 \mathrm{Mb}$ del & 16p11. 2.5 Mb dup & $16 p 11.2595 \mathrm{~kb} \mathrm{del}^{\mathrm{a}}$ & 3p26.3 1.6 Mb dup & CDKL5; SCN8A; SCN2A; \\
\hline & 2q23.1 4.1 Mb del & $3 q 111.64$ Mb dup & Xp22.11 del & 7q11.23 1.4 Mb del & ALG13; DNM1; HDAC4 \\
\hline & 1q21 2.1 Mb dup & & & 14q12 3.3 Mb dup & \\
\hline & & & Inherited: & $14 q 32.3317$ kb dup & Other candidate genes: \\
\hline & & & 2 q32.3 $421 \mathrm{~kb}$ del & 15q11-q13 5.3 Mb dup & CACN1A; CHD2; FLNA; \\
\hline & & & & $19 q 121.3 \mathrm{Mb}$ del & GABRB1; GRIN1; GRIN2B; \\
\hline & & & & 20p13 1.9 Mb del & HNRNPU; IQSEC2; MTOR; \\
\hline & & & & $21 \mathrm{q} 211.3 \mathrm{Mb}$ dup & NEDD4L \\
\hline & & & & 21q21 1.3 Mb dup & \\
\hline & & & & Xp22.2 435 kb dup & \\
\hline & & & & Unknown & \\
\hline & & & & $2 q 24.321 .5 \mathrm{Mb}$ dup & \\
\hline
\end{tabular}

The two CNV observed in one proband.

${ }^{\mathrm{b}}$ Size is unknown.

del, deletion; dup, duplication.

to be defined. Because of the haploinsufficiency of $M B D 5$ in humans, an interesting question for investigation is whether the $M b d 5$ heterozygous mutant mice recapitulate the clinical features observed in humans, including IS. HNRNPU belongs to the family of heterogeneous nuclear ribonucleoproteins (hnRNPs) proteins that associate with nascent RNA polymerase II transcripts to form hnRNP complexes [46]. HNRNPU is thought to influence the structure of hnRNA and to participate in pre-mRNA processing but the function of HNRNPU in the brain has not been studied.

Generalized seizures have been recognized as one of the common comorbidities in ASD [47]. The clinical association between ASD and IS is also well recognized [2]. However, the exact molecular link between ASD and seizure remains poorly understood. The topic as to whether seizure or autism is the primary pathophysiology is a subject for ongoing debate. In cases with both IS and ASD, chronologically, the infantile spasms usually present before the signs and symptoms of autistic features emerge, thus the pathophysiology of IS may be the primary mechanism for ASD. However, it is equally possible that different pathophysiology at different developmental stages is responsible for IS and ASD. Together with other genes such as TSC1/2 and CDKL5, the implication of $M B D 5$, a strong ASD causative gene, in IS supports the molecular link between ASD and IS. Our findings certainly support a medical re-sequencing study of $M B D 5$ in a large number of children with IS to consolidate the role of $M B D 5$ in IS, and provide an opportunity to further dissect the molecular link between the IS and ASD.

\section{Conclusions}

We reported the first genome wide copy number variation analysis in Chinese children with IS. Our findings of the CNVs of 1q21.1 gain and 1q44, 2q31.1, 17p13.3 loss in Chinese IS children not only support the pathogenic CNVs are conserved across different ethnic backgrounds, but also specifically implicate the MBD5 and HNRNPU genes in IS. The finding of MBD5 in both ASD and IS also offers the opportunity to dissect the shared molecular pathophysiology between ASD and infantile spasms.

\section{Additional file}

Additional file 1: Table S1. Clinical characteristics of studying subjects in this study. Table S2. The primers for validation of rare CNVs by real-time PCR. Table S3. The primers for Sanger sequencing of MBD5 and ORC4 genes.

\section{Abbreviations}

IS: Infantile spasms; ASD: Autism spectrum disorder; CNV: Copy number variation; $\mathrm{CGH}$ : Comparative genomic hybridization. 


\section{Competing interests}

All authors declare no conflict interest.

\section{Authors' contributions}

$X D, Y A, L Y, R L, Y Q, X G$ conducted the experiments and data analysis. $X D, L Y$, $S Z$ and DS contributed to the patient recruitments. BLW contributed to the array CGH analysis. DX, YA, YHJ and YW designed the experiments, data analysis, and wrote the manuscript. All authors read and approved the final manuscript.

\section{Authors' information}

Ms. Xiaonan Du, the first author of paper, is the PhD student of Children's Hospital of Fudan University. This study is part of her dissertation work. Dr. Yi Wang, the corresponding author of the manuscript, is Professor and Division Chief of Neurology, Vice President of Children's Hospital of Fudan University. Dr. Bai-lin WU is Assistant Professor and the Director of Laboratory of Medicine at Boston Children's Hospital, Harvard School of Medicine. Dr. Yong-hui Jiang is Associate Professor of Pediatrics and Neurobiology at Duke University School of Medicine.

\section{Acknowledgements}

We would like to thank all of families who participated in this project. This study was supported by a grant from the National Natural Science Foundation of China (NSCF, 81071116) and the Shanghai Committee of Science and Technology (STCSM, 12XD1401100). YA is supported by the 973 National Basic Research Program of China (2010CB529601). YHJ is supported by NIH 5R01MH098114-03.

\section{Author details}

${ }^{1}$ Division of Neurology, Children's Hospital of Fudan University, 399 Wan Yuan Road, Shanghai 201102, China. ${ }^{2}$ Institute of Biomedical Sciences and MOE Key Laboratory of Contemporary Anthropology, Fudan University, Shanghai 200032, China. ${ }^{3}$ Boston Children's Hospital, Harvard Medical School, Boston, MA, USA ${ }^{4}$ Division of Medical Genetics, Department of Pediatrics and Neurobiology, Duke University School of Medicine, 905 S. LaSalle ST, Durham, NC 27710, USA.

Received: 10 January 2014 Accepted: 13 May 2014

Published: 29 May 2014

\section{References}

1. Pellock JM, Hrachovy R, Shinnar S, Baram TZ, Bettis D, Dlugos DJ, Gaillard WD, Gibson PA, Holmes GL, Nordl DR, O'Dell C, Shields WD, Trevathan E, Wheless JW: Infantile spasms: a U.S. consensus report. Epilepsia 2010, 51(10):2175-2189.

2. Saemundsen $E$, Ludvigsson $P$, Rafnsson $V$ : Risk of autism spectrum disorders after infantile spasms: a population-based study nested in a cohort with seizures in the first year of life. Epilepsia 2008, 49(11):1865-1870.

3. Paciorkowski AR, Thio LL, Dobyns WB: Genetic and biologic classification of infantile spasms. Pediatr Neurol 2011, 45(6):355-367.

4. Epi4K Consortium; Epilepsy Phenome/Genome Project, Allen AS, Berkovic SF, Cossette P, Delanty N, Dlugos D, Eichler EE, Epstein MP, Glauser T, Goldstein DB, Han Y, Heinzen EL, Hitomi Y, Howell KB, Johnson MR, Kuzniecky R, Lowenstein DH, Lu YF, Madou MR, Marson AG, Mefford HC, Esmaeeli Nieh S, O'Brien TJ, Ottman R, Petrovski S, Poduri A, Ruzzo EK, Scheffer IE, Sherr EH: De novo mutations in epileptic encephalopathies. Nature 2013, 501(7466):217-221.

5. Kato M: A new paradigm for West syndrome based on molecular and cell biology. Epilepsy Res 2006, 70(Suppl 1):S87-S95.

6. Brunetti-Pierri N, Paciorkowski AR, Ciccone R, Della Mina E, Bonaglia MC, Borgatti R, Schaaf CP, Sutton VR, Xia Z, Jelluma N, Ruivenkamp C, Bertrand M, de Ravel TJ, Jayakar P, Belli S, Rocchetti K, Pantaleoni C, D'Arrigo S, Hughes J, Cheung SW, Zuffardi O, Stankiewicz P: Duplications of FOXG1 in $14 q 12$ are associated with developmental epilepsy, mental retardation, and severe speech impairment. Eur J Human Gen 2011, 19(1):102-107.

7. Paciorkowski AR, Thio LL, Rosenfeld JA, Gajecka M, Gurnett CA, Kulkarni S, Chung WK, Marsh ED, Gentile M, Reggin JD, Wheless JW, Balasubramanian S, Kumar R, Christian SL, Marini C, Guerrini R, Maltsev N, Shaffer LG, Dobyns WB: Copy number variants and infantile spasms: evidence for abnormalities in ventral forebrain development and pathways of synaptic function. Eur J Human Gen 2011, 19(12):1238-1245.
8. Tiwari VN, Sundaram SK, Chugani HT, Huq AH: Infantile spasms are associated with abnormal copy number variations. J Child Neurol 2013, 28(10):1191-1196.

9. Heinzen EL, Radtke RA, Urban TJ, Cavalleri GL, Depondt C, Need AC, Walley NM, Nicoletti P, Ge D, Catarino CB, Duncan JS, Kasperaviciūte D, Tate SK, Caboclo LO, Sander JW, Clayton L, Linney KN, Shianna KV, Gumbs CE, Smith J, Cronin KD, Maia JM, Doherty CP, Pandolfo M, Leppert D, Middleton LT, Gibson RA, Johnson MR, Matthews PM, Hosford D, et al: Rare deletions at $16 \mathrm{p} 13.11$ predispose to a diverse spectrum of sporadic epilepsy syndromes. Am J Hum Genet 2010, 86(5):707-718.

10. Helbig I, Mefford HC, Sharp AJ, Guipponi M, Fichera M, Franke A, Muhle H, de Kovel C, Baker C, von Spiczak S, Kron KL, Steinich I, Kleefuss-Lie AA, Leu C, Gaus V, Schmitz B, Klein KM, Reif PS, Rosenow F, Weber Y, Lerche H, Zimprich F, Urak L, Fuchs K, Feucht M, Genton P, Thomas P, Visscher F, de Haan GJ, Møller RS, et al: 15q13.3 microdeletions increase risk of idiopathic generalized epilepsy. Nat Genet 2009, 41(2):160-162.

11. Mefford HC, Mulley JC: Genetically complex epilepsies, copy number variants and syndrome constellations. Genome medicine 2010, 2(10):71.

12. Shen Y, Dies KA, Holm IA, Bridgemohan C, Sobeih MM, Caronna EB, Miller KJ, Frazier JA, Silverstein I, Picker J, Weissman L, Raffalli P, Jeste S, Demmer LA, Peters HK, Brewster SJ, Kowalczyk SJ, Rosen-Sheidley B, McGowan C, Duda AW 3rd, Lincoln SA, Lowe KR, Schonwald A, Robbins M, Hisama F, Wolff R, Becker R, Nasir R, Urion DK, Milunsky JM, et al: Clinical genetic testing for patients with autism spectrum disorders. Pediatrics 2010, 125(4):e727-e735.

13. Lin CH, Lin YC, Wu JY, Pan WH, Chen YT, Fann CS: A genome-wide survey of copy number variations in Han Chinese residing in Taiwan. Genomics 2009, 94(4):241-246.

14. Lou H, Li S, Yang Y, Kang L, Zhang X, Jin W, Wu B, Jin L, Xu S: A map of copy number variations in Chinese populations. PLoS One 2011, 6(11):e27341.

15. Park H, Kim Jl, Ju YS, Gokcumen O, Mills RE, Kim S, Lee S, Suh D, Hong D, Kang HP, Yoo YJ, Shin JY, Kim HJ, Yavartanoo M, Chang YW, Ha JS, Chong W, Hwang GR, Darvishi K, Kim H, Yang SJ, Yang KS, Kim H, Hurles ME, Scherer SW, Carter NP, Tyler-Smith C, Lee C, Seo JS: Discovery of common Asian copy number variants using integrated high-resolution array $\mathrm{CGH}$ and massively parallel DNA sequencing. Nat Genet 2010, 42(5):400-405

16. Dobyns WB, Das S: LIS1-Associated Lissencephaly/Subcortical Band Heterotopia. In GeneReviews(R). Edited by Pagon RA, Adam MP, Ardinger $\mathrm{HH}$, Bird TD, Dolan CR, Fong CT, Smith RJH, Stephens K. Seattle (WA): 1993-2014 PMID:20301752.

17. Guerrini R, Carrozzo R: Epilepsy and genetic malformations of the cerebral cortex. Am J Med Genet 2001, 106(2):160-173.

18. Epi KC: Epi4K: gene discovery in 4,000 genomes. Epilepsia 2012, 53(8):1457-1467

19. Haldeman-Englert C, Jewett T: 1q21.1 Microdeletion. In GeneReviews(R). Edited by Pagon RA, Adam MP, Ardinger HH, Bird TD, Dolan CR, Fong CT, Smith RJH, Stephens K. Seattle (WA): 1993-2014. PMID: 21348049.

20. Talkowski ME, Mullegama SV, Rosenfeld JA, van Bon BW, Shen Y, Repnikova EA, Gastier-Foster J, Thrush DL, Kathiresan S, Ruderfer DM, Chiang C, Hanscom C, Ernst C, Lindgren AM, Morton CC, An Y, Astbury C, Brueton LA, Lichtenbelt KD, Ades LC, Fichera M, Romano C, Innis JW, Williams CA, Bartholomew D, Van Allen Ml, Parikh A, Zhang L, Wu BL, Pyatt RE, et al: Assessment of 2q23.1 microdeletion syndrome implicates MBD5 as a single causal locus of intellectual disability, epilepsy, and autism spectrum disorder. Am J Hum Genet 2011, 89(4):551-563.

21. van Bon BW, Koolen DA, Brueton L, McMullan D, Lichtenbelt KD, Adès LC, Peters G, Gibson K, Moloney S, Novara F, Pramparo T, Dalla Bernardina B, Zoccante L, Balottin U, Piazza F, Pecile V, Gasparini P, Guerci V, Kets M, Pfundt R, de Brouwer AP, Veltman JA, de Leeuw N, Wilson M, Antony J, Reitano S, Luciano D, Fichera M, Romano C, Brunner HG, et al: The 2q23.1 microdeletion syndrome: clinical and behavioural phenotype. Eur J Hum Gen 2010, 18(2):163-170

22. Bonnet C, Ali Khan A, Bresso E, Vigouroux C, Béri M, Lejczak S, Deemer B, Andrieux J, Philippe C, Moncla A, Giurgea I, Devignes MD, Leheup B, Jonveaux P: Extended spectrum of MBD5 mutations in neurodevelopmental disorders. Eur J Hum Gen 2013, 21(12):1457-1461.

23. Hodge JC, Mitchell E, Pillalamarri V, Toler TL, Bartel F, Kearney HM, Zou YS, Tan WH, Hanscom C, Kirmani S, Hanson RR, Skinner SA, Rogers RC, Everman DB, Boyd E, Tapp C, Mullegama SV, Keelean-Fuller D, Powell CM, Elsea SH, 
Morton CC, Gusella JF, DuPont B, Chaubey A, Lin AE, Talkowski ME: Disruption of MBD5 contributes to a spectrum of psychopathology and neurodevelopmental abnormalities. Mol Psychiatry 2014, 19(3):368-379.

24. Shichiji M, Ito Y, Shimojima K, Nakamu H, Oguni H, Osawa M, Yamamoto T: A cryptic microdeletion including MBD5 occurring within the breakpoint of a reciprocal translocation between chromosomes 2 and 5 in a patient with developmental delay and obesity. Am J Med Genet A 2013, 161A(4):850-855.

25. Brunetti-Pierri N, Berg JS, Scaglia F, Belmont J, Bacino CA, Sahoo T, Lalani SR, Graham B, Lee B, Shinawi M, Shen J, Kang SH, Pursley A, Lotze T, Kennedy G, Lansky-Shafer S, Weaver C, Roeder ER, Grebe TA, Arnold GL, Hutchison T, Reimschisel T, Amato S, Geragthy MT, Innis JW, Obersztyn E, Nowakowska B, Rosengren SS, Bader PI, Grange DK, et al: Recurrent reciprocal 1q21.1 deletions and duplications associated with microcephaly or macrocephaly and developmental and behavioral abnormalities. Nat Genet 2008, 40(12):1466-1471.

26. Mefford HC, Sharp AJ, Baker C, Itsara A, Jiang Z, Buysse K, Huang S, Maloney VK, Crolla JA, Baralle D, Collins A, Mercer C, Norga K, de Ravel T, Devriendt K, Bongers EM, de Leeuw N, Reardon W, Gimelli S, Bena F, Hennekam RC, Male A, Gaunt L, Clayton-Smith J, Simonic I, Park SM, Mehta SG, Nik-Zainal S, Woods CG, Firth HV, et al: Recurrent rearrangements of chromosome 1q21.1 and variable pediatric phenotypes. N Engl J Med 2008, 359(16):1685-1699.

27. Dolcetti A, Silversides CK, Marshall CR, Lionel AC, Stavropoulos DJ, Scherer SW, Bassett AS: 1q21.1 Microduplication expression in adults. Genet Med 2013, 15(4):282-289.

28. Kao WT, Wang Y, Kleinman JE, Lipska BK, Hyde TM, Weinberger DR, Law AJ: Common genetic variation in Neuregulin 3 (NRG3) influences risk for schizophrenia and impacts NRG3 expression in human brain. Proc Natl Acad Sci U S A 2010, 107(35):15619-15624.

29. Tang CS, Cheng G, So MT, Yip BH, Miao XP, Wong EH, Ngan ES, Lui VC, Song YQ, Chan D, Cheung K, Yuan ZW, Lei L, Chung PH, Liu XL, Wong KK, Marshall CR, Scherer SW, Cherny SS, Sham PC, Tam PK, Garcia-Barceló MM: Genome-wide copy number analysis uncovers a new HSCR gene: NRG3. PLoS Genet 2012, 8(5):e1002687.

30. Yasui S, Tsuzaki K, Ninomiya H, Floricel F, Asano Y, Maki H, Takamura A Nanba E, Higaki K, Ohno K: The TSC1 gene product hamartin interacts with NADE. Mol Cell Neurosci 2007, 35(1):100-108.

31. Faletra F, D'Adamo AP, Santa Rocca M, Carrozzi M, Perrone MD, Pecile V, Gasparini P: Does the 1.5 Mb microduplication in chromosome band Xp22.31 have a pathogenetic role? New contribution and a review of the literature. Am J Med Genet A 2012, 158A(2):461-464.

32. Liu P, Erez A, Nagamani SC, Bi W, Carvalho CM, Simmons AD, Wiszniewska $J$, Fang P, Eng PA, Cooper ML, Sutton VR, Roeder ER, Bodensteiner JB, Delgado MR, Prakash SK, Belmont JW, Stankiewicz P, Berg JS, Shinawi M, Patel A, Cheung SW, Lupski JR: Copy number gain at Xp22.31 includes complex duplication rearrangements and recurrent triplications. Hum Mol Genet 2011, 20(10):1975-1988.

33. Bird TD, Pagon RA, Adam MP, Ardinger HH, Bird TD, Dolan CR, Fong CT, Smith RJH, Stephens K: Hereditary Neuropathy with Liability to Pressure Palsies. In GeneReviews(R). Seattle (WA): 1993-2014. PMID: 20301566.

34. Basu S, Totty NF, Irwin MS, Sudol M, Downward J: Akt phosphorylates the Yes-associated protein, YAP, to induce interaction with 14-3-3 and attenuation of p73-mediated apoptosis. Mol Cell 2003, 11(1):11-23.

35. Hatzimanolis A, McGrath JA, Wang R, Li T, Wong PC, Nestadt G, Wolyniec $P S$, Valle D, Pulver AE, Avramopoulos D: Multiple variants aggregate in the neuregulin signaling pathway in a subset of schizophrenia patients. Trans Psych 2013, 3:e264.

36. Meier S, Strohmaier J, Breuer R, Mattheisen M, Degenhardt F, Mühleisen TW, Schulze TG, Nöthen MM, Cichon S, Rietschel M, Wüst S: Neuregulin 3 is associated with attention deficits in schizophrenia and bipolar disorder. Int J Neuropsycho 2013, 16(3):549-556.

37. Mefford HC, Yendle SC, Hsu C, Cook J, Geraghty E, McMahon JM, Eeg-Olofsson O, Sadleir LG, Gill D, Ben-Zeev B, Lerman-Sagie T, Mackay M, Freeman JL, Andermann E, Pelakanos JT, Andrews I, Wallace G, Eichler EE, Berkovic SF, Scheffer IE: Rare copy number variants are an important cause of epileptic encephalopathies. Ann Neurol 2011, 70(6):974-985.

38. Thierry G, Bénéteau C, Pichon O, Flori E, Isidor B, Popelard F, Delrue MA, Duboscq-Bidot L, Thuresson AC, van Bon BW, Cailley D, Rooryck C, Paubel A, Metay C, Dusser A, Pasquier L, Béri M, Bonnet C, Jaillard S, Dubourg C, Tou B, Quéré MP, Soussi-Zander C, Toutain A, Lacombe D, Arveiler B, de Vries BB,
Jonveaux P, David A, Le Caignec C: Molecular characterization of 1q44 microdeletion in 11 patients reveals three candidate genes for intellectual disability and seizures. Am J Med Genet A 2012, 158A(7):1633-1640.

39. Poot M, Kas MJ: Antisense may make sense of 1q44 deletions, seizures, and HNRNPU. Am J Med Genet A 2013, 161A(4):910-912.

40. Carvill GL, Heavin SB, Yendle SC, McMahon JM, O'Roak BJ, Cook J, Khan A, Dorschner MO, Weaver M, Calvert S, Malone S, Wallace G, Stanley T, Bye AM, Bleasel A, Howell KB, Kivity S, Mackay MT, Rodriguez-Casero V, Webster R, Korczyn A, Afawi Z, Zelnick N, Lerman-Sagie T, Lev D, Møller RS, Gill D, Andrade DM, Freeman $J$, Sadleir LG, et al: Targeted resequencing in epileptic encephalopathies identifies de novo mutations in CHD2 and SYNGAP1. Nat Genet 2013, 45(7):825-830.

41. Suls A, Jaehn JA, Kecskés A, Weber Y, Weckhuysen S, Craiu DC, Siekierska A, Djémié T, Afrikanova T, Gormley P, von Spiczak S, Kluger G, lliescu CM, Talvik T, Talvik I, Meral C, Caglayan HS, Giraldez BG, Serratosa J, Lemke JR, Hoffman-Zacharska D, Szczepanik E, Barisic N, Komarek V, Hjalgrim H, Møller RS, Linnankivi T, Dimova P, Striano P, Zara F, et al: De novo loss-of-function mutations in CHD2 cause a fever-sensitive myoclonic epileptic encephalopathy sharing features with Dravet syndrome. Am J Hum Genet 2013, 93(5):967-975.

42. Fryns JP, de Ravel TJ: London Dysmorphology Database, London Neurogenetics Database and Dysmorphology Photo Library on CD-ROM [Version 3] 2001R. M. Winter, M. Baraitser, Oxford University Press, ISBN 019851-780, pound sterling 1595. Hum Genet 2002, 111(1):113.

43. Verloes A, Dresse MF, Keutgen H, Asplund C, Smith Cl: Microphthalmia, facial anomalies, microcephaly, thumb and hallux hypoplasia, and agammaglobulinemia. Am J Med Genet 2001, 101(3):209-212.

44. Miltenberger-Miltenyi $\mathrm{G}$, Laccone F: Mutations and polymorphisms in the human methyl CpG-binding protein MECP2. Hum Mutat 2003, 22(2):107-115

45. Du Y, Liu B, Guo F, Xu G, Ding Y, Liu Y, Sun X, Xu G: The essential role of $\mathrm{Mbd} 5$ in the regulation of somatic growth and glucose homeostasis in mice. PLoS One 2012, 7(10):e47358.

46. Polo SE, Blackford AN, Chapman JR, Baskcomb L, Gravel S, Rusch A, Thomas A, Blundred R, Smith P, Kzhyshkowska J, Dobner T, Taylor AM, Turnell AS, Stewart GS, Grand RJ, Jackson SP: Regulation of DNA-end resection by hnRNPU-like proteins promotes DNA double-strand break signaling and repair. Mol Cell 2012, 45(4):505-516.

47. Amiet C, Gourfinkel-An I, Laurent C, Bodeau N, Genin B, Leguern E, Tordjman S, Cohen D: Does epilepsy in multiplex autism pedigrees define a different subgroup in terms of clinical characteristics and genetic risk? Molecular autism 2013, 4(1):47.

doi:10.1186/1471-2350-15-62

Cite this article as: Du et al:: A genomic copy number variant analysis implicates the MBD5 and HNRNPU genes in Chinese children with infantile spasms and expands the clinical spectrum of $2 q 23.1$ deletion. BMC Medical Genetics 2014 15:62.

\section{Submit your next manuscript to BioMed Central and take full advantage of:}

- Convenient online submission

- Thorough peer review

- No space constraints or color figure charges

- Immediate publication on acceptance

- Inclusion in PubMed, CAS, Scopus and Google Scholar

- Research which is freely available for redistribution 